\title{
SimUlation OF ViRTUAL MACHINE TOOL DURING THE MACHINE DESIGN
}

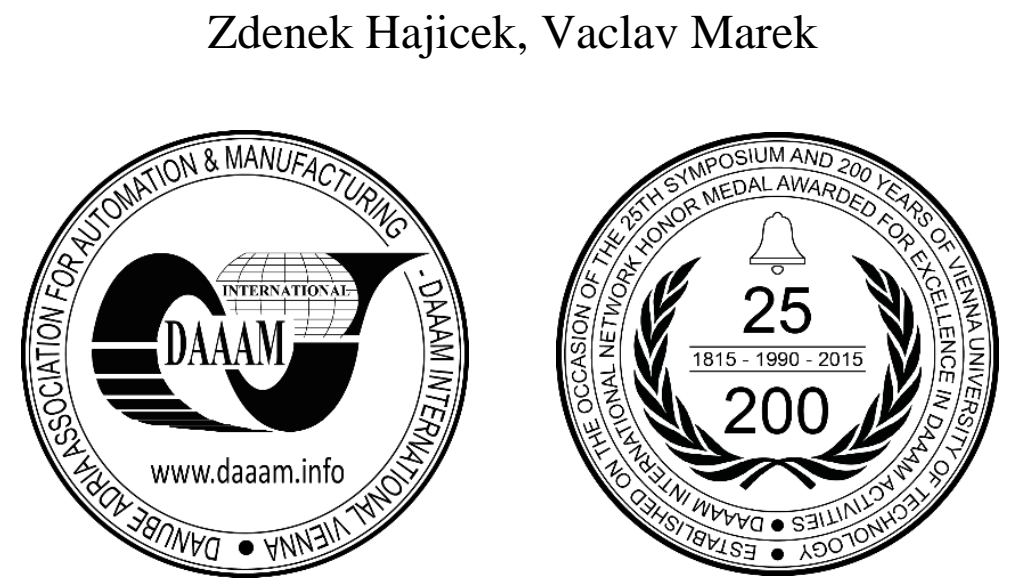

This Publication has to be referred as: Hajicek, Z[denek] \& Marek, V[aclav] (2017). Simulation of Virtual Machine Tool During the Machine Design, Proceedings of the 28th DAAAM International Symposium, pp.0555-0560, B. Katalinic (Ed.), Published by DAAAM International, ISBN 978-3-902734-11-2, ISSN 1726-9679, Vienna, Austria DOI: $10.2507 / 28$ th.daaam.proceedings.078

\begin{abstract}
This paper deals with the simulation of CNC machine tools. The main focus is to develop a Case Study for a new virtual concept of Horizontal CNC Machine Tool. A virtual Machine Tool uses the main properties of a real machine. The goal is to simulate the functionality of the machine in virtual phases. This method is intended for complex and very expensive machines like Milling and Boring Machine Tools with numerous accessories. The current trend is to sell Machine Tools and equipment with complete technology of machining. Customers prefer a virtual Case Study of CNC technology. The idea of virtual prototyping is realized if the behaviour of the virtual Machine Tool is in compliance with real machine.
\end{abstract}

Keywords: Virtual Machine Tool; CNC Machine Tools; CSE Driver; Postprocessor

\section{Introduction}

The current trend in machine manufacturing is to deliver Machine Tools with a turnkey solution. This solution is based on a typical customer part and CNC technology. This solution provides the framework for the Case and Time Study. This Case Study consists of the Machine Tool, technical equipment and CNC technology in one complex 3D layout.

The main purpose of the Case Study is to guarantee reliable information about the future behaviour of the Machine Tool. The Time Study is the analysis of time in CNC technology for typical customer part. The result of this study is the timing of each CNC operation, usage of tool and machine accessories in one document. These studies are very important elements for a lot of tenders in industrial practice.

The main problem is to simulate behaviour and functionality of CNC Machine tool in virtual phases. CAD/CAM system NX with PLM Teamcenter is used for the methodology of Creating Machine Tool Simulator and virtual verification like one complex solution. This Machine Tool Simulator uses main property axis and real kinematics of a machine. The solution has been demonstrated for the Skoda Machine HCW 1000 and the application Automatic Tool Change with Industrial Robot. 


\subsection{Literature overview}

Modern machine tools are very complex Mechatronical Systems. The capability and efficiency of a machine tool are mainly determined by its kinematics, structural dynamics, computer numerical control system and the machining process [1]. The CNC system consists of a computer, power electronic components, such as motor amplifiers and electronic circuits, and servo actuators. The computer control unit receives ISO standard NC-programs which describe the tool path geometry, tool number, feed and spindle speed at each path segment [2], [3]. The simulation of the CNC system involves virtual modelling of the machine tool kinematics and feed drive dynamics, update of the workpiece geometry as the material is removed and motions of the drives and auxiliary units, such as tool and pallet changes. In short, the rigid body motion of the machine tool and the CNC functions must be predicted as the workpiece is produced in order to realize a Virtual CNC system [1].

Once the NC Program is generated in a CAD/CAM environment, the present Virtual CNC technology allows the geometric update of the workpiece as the tool cuts the material at each NC block. In addition, the solid model of the machine tool, its multi-axis kinematics and the location of fixtures can be displayed in the CAD environment [4], [5].

The present technology of NC-path simulation allows the prediction of tool collision spots and correctness of the NC program by checking path errors and gauging on the workpiece surface graphically. Lauwers et al. [6], [7], [8], [9] take the CL file from the CAD system and simulate the machine motion by modelling the kinematics of the machine tool for collision detection and avoidance. In some commercial controllers machining simulation systems are integrated. During machining the simulation system runs a number of blocks ahead, and if there is a danger of a collision, the controller stops the machine immediately [1].

CSE Simulator consists of:

- Simplified 3D Layout of Machine Tool with all accessories and equipment

- Machine Tool Kinematic Structure model

- MCS Driver programmed for current Machine Controller

- NX Postprocessor programmed for current Machine Controller and simulation

- CSE Simulator implemented in NX CAM environment

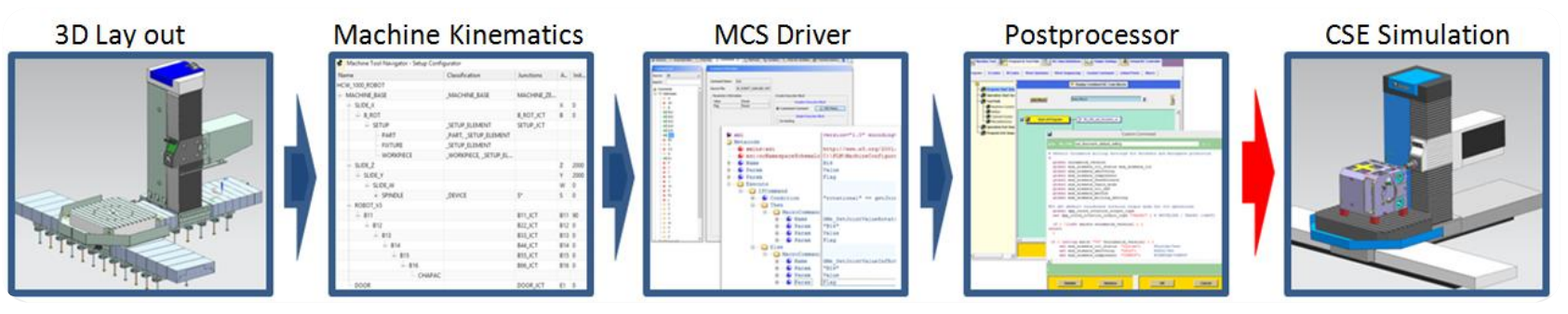

Fig. 1. Segments of Virtual Machine Tool (CSE Simulator)

\section{Current process}

\subsection{Current status of Layout Design and simulation of Machine Tools}

In the beginning of this project the company used one 3D Layout in three departments: Sales, Design and Customer Technology. These departments have different requirements. In the Sales Department, users need a very quick Layout of Machine for new tender and possibility of making revise a version. The Customer Technology Department needs a simple 3D assembly of Machine Tool for the preparation of Time and Case Study. This Case Study may consist of CAM Technology with all Machine equipment and accessories. This technology is supported by CSE Simulation for virtual verification of developed solution.

\subsection{Current problems}

The Machine Layout came from Design department in a non-optimized stated without simplified parts of a machine. If Application Engineer prepares a Collision Analysis of CNC technology the calculation will take long because the collision parts are not simplified. The CSE Collision Analysis builds a special mesh from collision parts automatically in the background. The analysis checks the penetration of these two meshes in real time of machine simulation. If we use non-simplified machine parts in this simulation (like Column with inside Ribs - Fig. 2) the mesh will be unnecessary difficult. For faster calculation of CSE analysis, it is necessary to use a simple solid model without inside parts and complicated shapes. After that, the simulation will be more efficient. 
Disadvantages of current Layout Design and Technologic Studies:

- Not optimized 3D parts of Machine Tool Layout

- Bad quality of imported CAD data from Solid Edge ST2 to NX 10

- CAD data without Data Management

- Long time for the preparation of Machine Layouts

- Long time for the preparation of Technological Studies without any simulation

- Way to avoid mistakes in the preparation of CSE Simulation

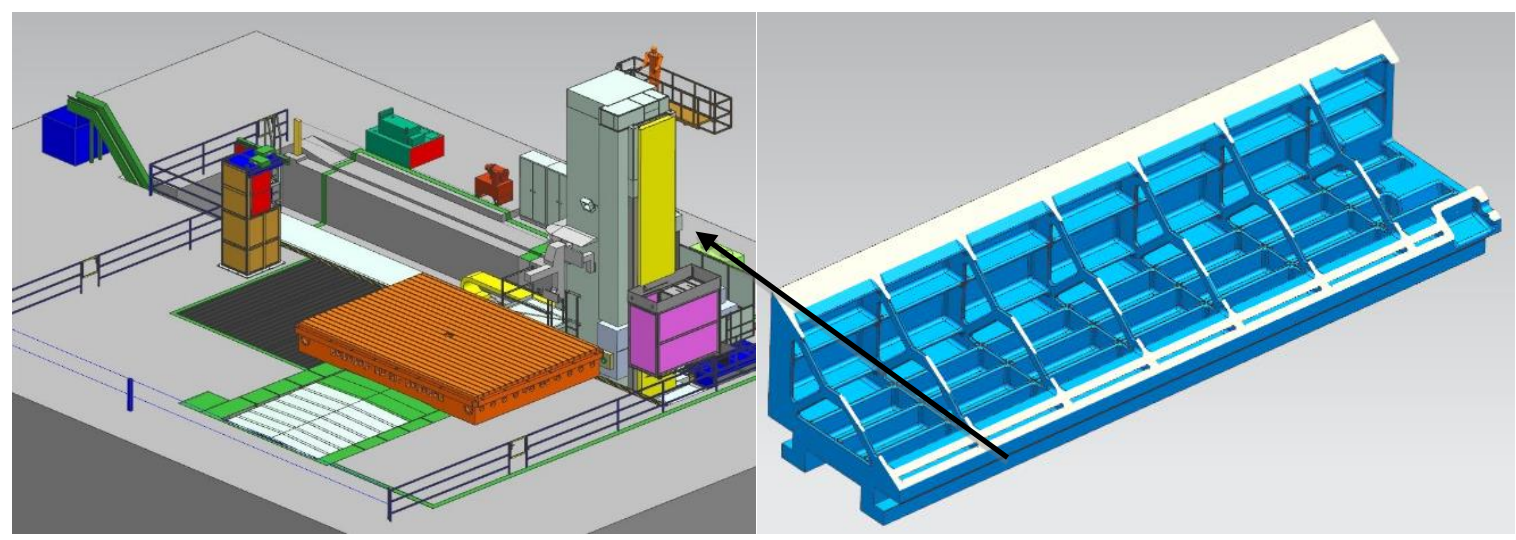

Fig. 1. Not optimized Machine 3D Layout and Column with Ribs

\subsection{Research in using Machine Tool Simulation in the company}

The main goal of this research is to create an application of ISV Simulation to design and develop of Heavy Machine Tools. The PLM System Teamcenter, NX CAD System, NX CAM System, NX ISV Simulation module are used to problem solving and the software the Post Builder is used for programming Postprocessors. PLM system Teamcenter is used for data administration and Approval Processes. NX CAD is used for the design of Machine Tool Layouts. NX CAM System is used for programming of CNC Technology and NX ISV module for CSE Simulation and verification of solution.

All these kinds of software are connected by one PLM platform in the company who is a producer of Heavy Machine Tools. To obtaining a contract is very complicated and lengthy.

The typical new contract starts by signing a new customer tender in the Heavy Engineering. This signing starts the workflow process in the company. The workflow is without CSE verification of solution and the time for the preparation of Machine Layout and Technology Studies is very long. These critical elements are eliminated by a more developed methodology of Automated Design 3D Layouts as well as Creating Machine Tool Simulator.

Main steps of new workflow for the contract:

- Design of Machine Tool Layout by new automated solution

- Customers revisions of the Machine Tool concept in PLM System

- Time and Case Study in CAM System

- CSE Verification of prepared solution

- Approved solution by customer and contract confirmation

- Design and production of new Horizontal Boring and Milling Machine Tool

- Assembly and tests of new Machine Tool

- Application Machine Tool in the customers company

\section{New methodology layout design and machine simulation}

\subsection{Methodology of Automated Design Machine Tool Layout}

This methodology is based on the principle of using simplified Machine Tool part from one shared library. This library is shaved in PLM database and is automatically integrated in NX CAD/CAM environment. The simplified Machine parts are designed as parametric model and this model can be driven by Excel table. The table contains only standard parameters of the machine dimension. The designer can put the machine part from the library. He can choose a current value of machine diameters from NX window and the model is automatically transformed to the recommended dimensions. The designer can assemble the Machine Layout very fast without using any Assembly Constrains. The component (Simplified Machine part) is automatically put on the correct position in the CAD assembly. This methodology reduces the design of Machine Layout from 30-40 hours to 4-8 hours. The time of preparation depends on the complexity of the Machine Tool. 


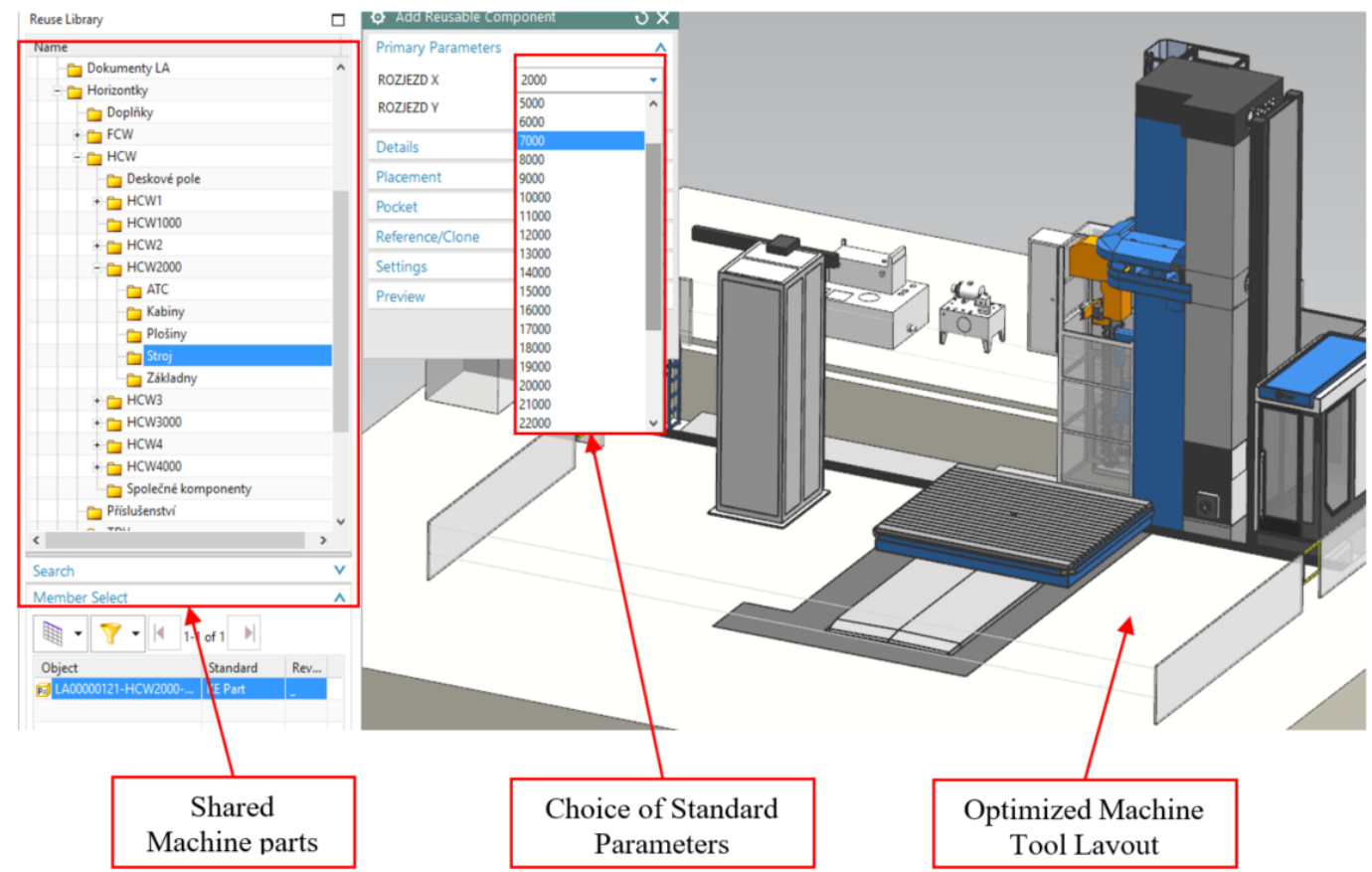

Fig. 3. Optimized Machine Tool Layout

\subsection{Methodology of Creating Machine Tool CSE Simulator}

This methodology is based on the principle of using Optimized Machine Tool Layout and CSE Template. The CSE Template consists of Machine Tool Kinematic structure (MTB), Postprocessor, MCS Driver and a service Library for each machine type. The Application Engineer can prepare Machine Kinematic in NX ISV module Machine Tool Builder. When creating the CSE Machine Tool Simulator, Application Engineer puts together CSE Template segments and new MTB Machine Tool. After that it is possible to implement a new CSE Simulator in NX CAM structure. The Workflow is described in the picture (Fig. 4).

If the new CSE Simulator is implemented in the NX CAM, the Application Engineer can prepare the customer CNC/CAM technology. The result of this methodology is a quick preparation of Time Study, Case Study and a verification of new Machine Tool.

All of these CSE Template elements are developed exactly for a producer of Heavy Machine Tools like Horizontal Boring and Milling Machines. These machines are very specific which makes the application of CNC technology difficult to implement. The new CSE Simulation is driven by the real CNC program and real CAM technology. This debugging, CNC program is possible to implement in real production line very quickly and safely.

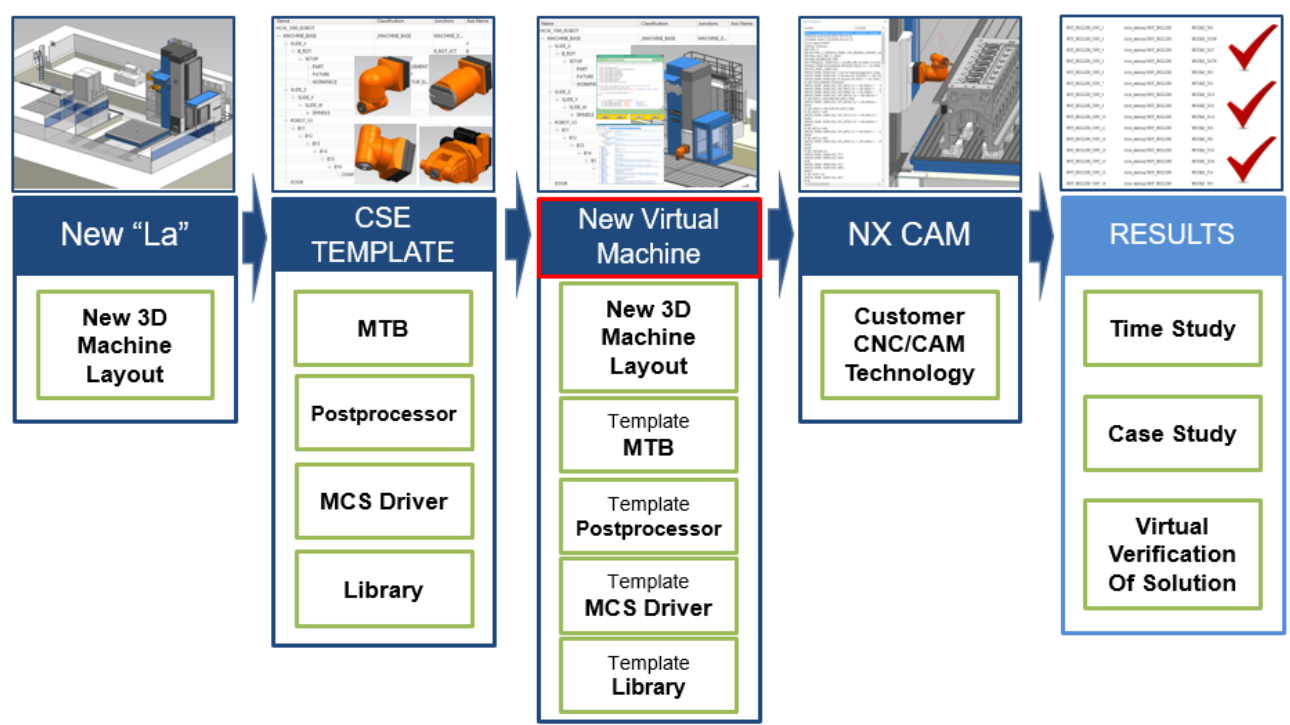

Fig. 4. Methodology of Creating Machine Tool Simulator 


\subsection{Sample calculation of the cost of the Machine Tool Layouts}

A designer needs 40 hours for the preparation of a standard type of Machine Tool Layout by using an original methodology. If the designer uses the methodology of Automated Design Machine Tool, the time for preparing the standard type machine is eight hours. For this sample, the calculation of the internal rate per hour for one designer is 20 Euros. If the designer has to prepare ten layouts in one month, the price will be very different. By using the original methodology the price will be 8,000 Euros for ten layouts. By using the methodology of Automated Design, the price will be 1,600 Euros (for ten Layouts). The new solution will save 640 Euros per one layout and 6,400 Euros per ten layouts. In general, the methodology of Automated Design Machine Layout reduces the time and the price in preparing the machine layout by $80 \%$.

\section{Application of CSE virtual machine simulation}

This application is focused on the development of the virtual Horizontal Milling Machine for machining a block of headstock for the Turning Machine SR1000. The concept of the 3D layout is designed for high usage of tools. This solution uses tools up to 432. The machine tool is designed for the continuous cycle of production. It consists of a Pallet System for Workpiece changing and the Automatic Tool Change with the Industrial Robot KR 90. This system consists of the three pallets. Only one pallet can be in the workplace at each time. The other two pallets are used for clamping workpiece because this part must be machined to all faces. The first pallet is used for main clamping workpiece position and the second is used for repositioning for bottom milling. This technology uses two CNC programs which are changed by the current Workpiece position.

The customer requirement is a continous production and all of the tools must be delivered twice. Before inserting the tool to the spindle or to the Carousel Tool Housing Pocket, the robot checks the tool by the laser measuring system. If the tool shows any signs of damage, the robot forwards the tool to the machine operator repairs or changes it completely.

For the design, the Tool Housing has been selected: Representative Tools depending on size, Base Tool (Length 200 mm, Diameter $22 \mathrm{~mm}$ ), Middle Tool (Length $320 \mathrm{~mm}$, Diameter $80 \mathrm{~mm}$ ) and Large Tool (Length $475 \mathrm{~mm}$, Diameter 300 $\mathrm{mm})$.

The industrial Robot uses the Tool Hydraulic Double Gripper with two pockets for tools. This Gripper can grasp two tools together due to the rapid tool change into the spindle. The robot with the Gripper must move to a changing position before the spindle, the first jaw mechanism removes the tool from the spindle, then it needs to rotate ninety degrees and the second jaw mechanism inserts new tool into the spindle. This movement takes a maximum of five seconds.

The Tool Housing is designed by three Carousels with three rotating shelves. This case study uses 144 Base Tools, 144 Middle Tools and 45 Large Tools. Altogether there are 333 mixed tools in one Tool Housing. The total time of this tool change simulation is 21 seconds which is also sufficient. The price of the solution is 190,000 Euros.

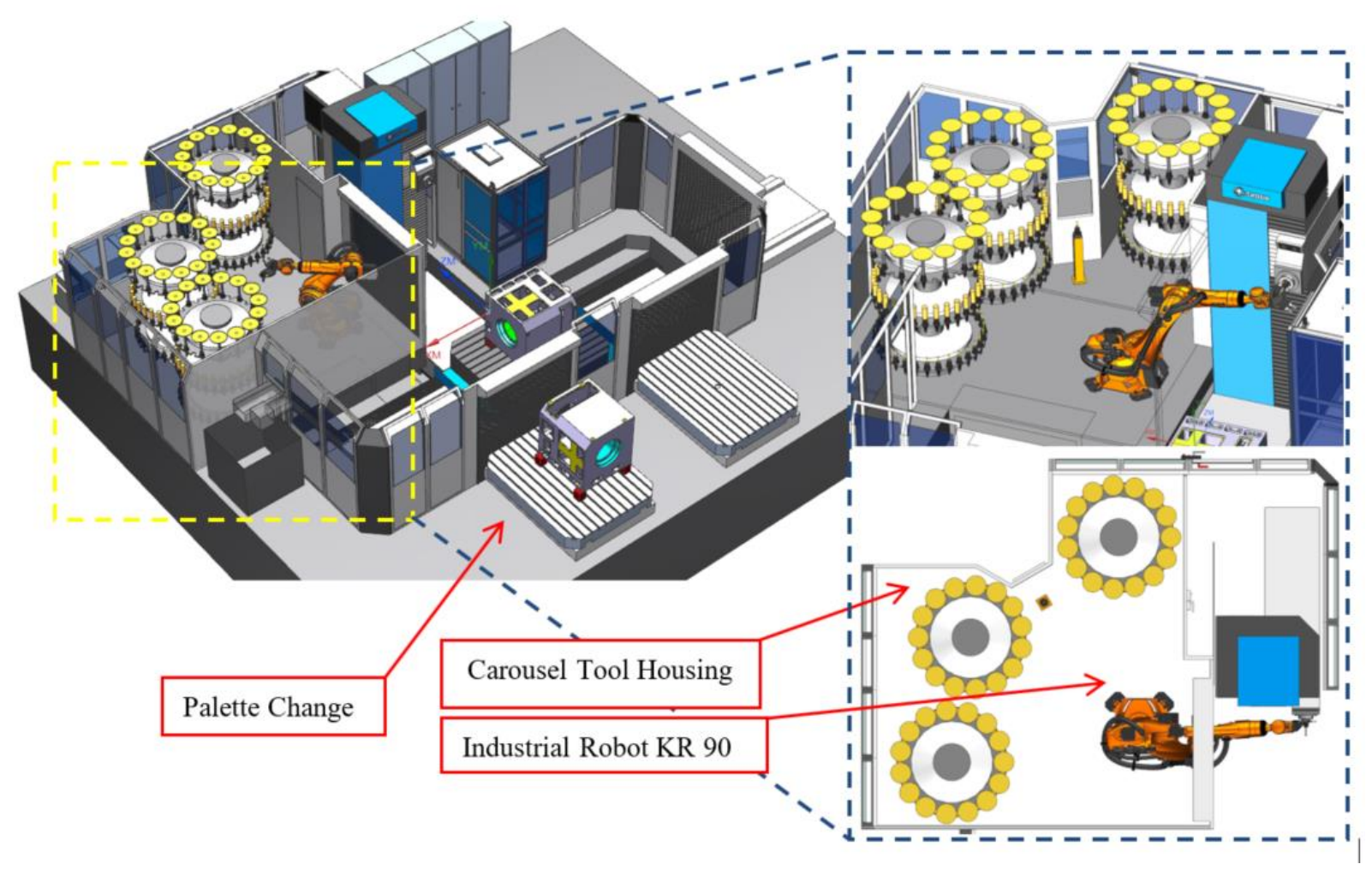

Fig. 5. CSE simulation of HCW 1000 and Robotic Tool Change with Carousel Arena 


\section{Conclusion and results}

This thesis describes the problem of the simulation of Machine Tools and the possibility of using in virtual prototyping. The thesis shows the current status about the Machine Tool Layouts design and what the main problem is in the verification of new Machine concepts. A current trend in the machine manufacturing is to deliver Machine tools with a turnkey solution. It is important to prepare solution which is based on a typical customer part and CNC technology.

The main research is focused on development of methodology Layout Design and Machine Tool simulation. The methodology of Layout Design allows the use of automated design of new Machine Tool concepts. This solution is based on the principle of using simplified Machine Tool parts from one shared library. The solution becomes the possibility of making a revised version of PLM system Teamcenter which guarantees a fast interaction of different departments in the company. This methodology reduces the time of the preparation and the price of the layout by $80 \%$.

The CSE Templates, MTB Machine Kinematics, Postprocessors and MCS Drivers for all kinematic types of Horizontal Boring and Milling Machines Tool are developed for Creating Machine Tool CSE Simulator methodology. The main principle of this methodology is used for the application of Horizontal Machine HCW 1000 and Robotic Tool Change with Carousel Arena. The application verifies a complicated arrangement of the machine in virtual phase. The result of the simulation is reflected the Case Study, Time Study and price calculation of Robotic Tool Change. The CSE Simulator is driven by the real CNC program and the real CAM Technology. This debugged CNC program is possible to implement in the real production very quickly and safely.

\subsection{Further research}

The main principles will be applied in next research of another type of Machine Tools like Heavy Lathe Machines, Heavy Grind Machines or CNC Mill and Turn Machines for Automotive Industry. This research will be focus on Virtual Drive and Virtual Control Systems for highest precision of Virtual Machine Tool Simulation.

\section{Acknowledgements}

The paper was supported by “ University of West Bohemia, Department of Machine Design, SGS 2017”

\section{References}

[1] Y. Altintas, C. Brecher, M. Weck, S. Witt, (2005), Virtual Machine Tool, CIRP Annals, 50/2: 115-138.,

[2] Pritschow, G., Altintas, Y., Javone, F., Koren, Y., Mitsuishi, M., Takata, S., Van Brussel, H., Weck, M., K.Yamazaki, 2001, Open Controller Architecture-past, present and future, Annals of the CIRP, 50/2: 446-463.

[3] Pritschow, G., Berkemer, J., Bürger, T., Croon, N., Korajda, B., Röck, S., (2003), Die simulierteWerkzeugmaschine, TagungsbandFertigungstechnischesKolloquium Stuttgart, 219-246

[4] Yeung, C.Ho, Altintas, Y., Erkorkmaz, K., (2004), Virtual CNC System, Part I: Architecture and Auto tuning of CNC Systems, Trans. ASME, J. Machine Tool Manuf. Eng.Manufacturing Science and Engineering.

[5] Yeung, C.Ho, Erkorkmaz, K., Altintas, Y., (2004), Virtual CNC System, Part II: Virtual Part Machining and auto correction of contouring errors, Trans. ASME, J. Manufacturing Science and Engineering.

[6] Kruth, J.P., Lauwers, B., Klewais, P., Dejonghe, P., (1999), "NC-postprocessing and NC-simulation for five-axis milling operations with automatic collision avoidance", International Journal for Manufacturing Science and Technology, 1(1), 1999, 12-18.

[7] Lauwers, B., Kruth, J.P., Dejonghe, P., Vreys, R., (2000), Efficient NC-programming of multi-axes milling machines through the integration of tool path generation and NC-simulation, Annals of the CIRP, 49/1/2000: 367-370.

[8] Lauwers, B., Van der Poorten, E., De Baerdemaeker, H., (2003), CAD/CAM based generation of collision free robot programs through the integration of a virtual machining environment, European Journal of Mechanical and Environmental Engineering,47/4: 215-220.

[9] Lauwers, B., Dejonghe, P., Kruth, J.P., (2003), Optimal and collision free tool posture in five-axis machining through the tight integration of tool path generation and machine simulation, Computer- Aided Design, 35 (5): 421 432.

[10] Ming, C.; Leu a Joshi A; (2008). Nx5 for engineering design. U.S. state of Missouri: Missouri Uneversity of Scieneceand Technology

[11] M. Wilson, Implementation of Robots Systems, United Kingdom, 2014, ISBN: 978-0-12-404733-4.

[12] F. Koenigsberger, J. Tlusty, Machine Tool Structures, Elsevier, 2013, 148316053X, 9781483160535.

[13] P. Janda, R. Polak, (2016). Virtual Prototyping and Optimization of Heavy Machine Tools, Published by DAAAM International, ISBN 978-3-902734-07-5, ISSN 1726-9679, Vienna, Austria 